\title{
Role of Diagnostic Hysterolaparoscopy in the Evaluation of Infertility - A Prospective Study from Telangana, India
}

\author{
Arjumand Bano ${ }^{1}$, Parvathapuram Sneha² \\ 1,2 Department of Obstetrics \& Gynaecology, Chalmeda Anand Rao Institute of \\ Medical Sciences, Bommakal, Karimnagar Telangana, India.
}

\section{ABSTRACT}

\section{BACKGROUND}

Infertility is a multidimensional health problem with social and economic consequences. Infertility affects about $10-15 \%$ of reproductive age couples. ${ }^{1}$ Hysterolaparoscopy is safe and effective method to diagnose infertility. The purpose of this study was to determine the role of diagnostic hysterolaparoscopy in the evaluation of infertility in Chalmeda Anand Rao Institute of Medical Sciences.

\section{METHODS}

A prospective hospital-based study was carried out in Chalmeda Anand Rao Institute of Medical Sciences over a period of 1 year from August 2019 to July 2020. Hysterolaparoscopy was done in 100 patients. Women aged 20 - 40 years with normal hormone profile without male factor infertility were included.

\section{RESULTS}

100 patients with infertility were undertaken, 70 (70\%) women had primary infertility and the remaining $30(30 \%)$ had secondary infertility. Ovarian pathology (30\%), endometriosis (23\%), tubal pathology (14\%) and pelvic adhesion (14\%) were the most well-known anomalies recognized in laparoscopy in both primary and secondary infertility. Uterine septum was major intrauterine pathology seen in two gatherings. Out of 12 patients having uterine malformations, most regular uterine malformation in both the gatherings was 9 uterine septum and 2 unicornuate and 1 was hypoplastic uterus.

\section{CONCLUSIONS}

Combined hysterolaparoscopy is a safe, effective, and reliable method in comprehensive evaluation of infertility. It helps in the diagnosis of pelvic pathology which is missed by routine pelvic examinations and basic investigations done for evaluation of infertility. Hysterolaparoscopy gives the added advantage of doing a therapeutic procedure in the same sitting. Thus, hysterolaparoscopy may be considered as gold standard and definitive investigative day-care procedure for evaluation of female infertility.

\section{KEY WORDS}

Hysteroscopy, Infertility, Laparoscopy
Corresponding Author: Dr. Parvathapuram Sneha, D/O Parvathapuram Ramesh, H. No. 3-9-46/8, Sharada Nagar Colony, Ramanthapur, Medchal, Hyderabad - 500013, Telangana, India. E-mail: sneha21041994@gmail.com

DOI: $10.14260 / \mathrm{jemds} / 2021 / 540$

How to Cite This Article:

Bano A, Sneha P. Role of diagnostic hysterolaparoscopy in the evaluation of infertility - a prospective study from Telangana, India. J Evolution Med Dent Sci 2021;10(32):2640-2644, DOI: $10.14260 /$ jemds $/ 2021 / 540$

Submission 14-10-2020,

Peer Review 07-07-2021,

Acceptance 14-07-2021,

Published 09-08-2021.

Copyright (C) 2021 Arjumand Bano et al. This is an open access article distributed under Creative Commons Attribution License [Attribution 4.0 International (CC BY 4.0)] 


\section{BACKGROUND}

Infertility, according to world health organization (WHO), is defined as lack of conception after 12 months or more of regular unprotected intercourse. ${ }^{1}$ Infertility affects about 10 $15 \%$ of reproductive age couples. ${ }^{1}$ Female factors contribute $40-45 \%$ in aetiology of infertility. ${ }^{2}$ Increasing lifestyle choices, stress and later age of marriage have made occurrence of infertility higher than couple of decades ago. ${ }^{3}$ Experience has shown that majority of pelvic pathology in infertile women is frequently not well appreciated by routine pelvic examinations and the usual diagnostic procedures. ${ }^{4}$

Accurate diagnosis is the first step towards a good treatment plan. Once the exact nature of the cause of infertility is identified, an optimal treatment plan can be individualized to meet the couple's fertility goals. ${ }^{4}$ The capacity to see and control the uterus, fallopian tubes and ovaries during laparoscopy has made it a fundamental piece of infertility assessment. Likewise, envisioning the uterine cavity and distinguishing the conceivable pathology has made hysteroscopy a similarly significant device in infertility assessment.

The subject of tubal morphology and patency, ovarian morphology, any unsuspected pelvic pathology, and uterine anomalies would all be able to be settled with precision at one meeting by utilizing a joined hysterolaparoscopy. Additionally, hysteroscopic guided biopsy and therapeutic procedures like polypectomy, myomectomy, septal resection, and adhesiolysis can be done in the same sitting. Currently, the gold standard diagnosis and treatment of infertility is laparoscopy and hysteroscopy.

This study was undertaken to evaluate the role of diagnostic hysterolaparoscopy in the comprehensive work up of infertility, which would help in planning appropriate management.

\section{METHODS}

This is a prospective hospital-based study conducted at Chalmeda Anand Rao Institute of Medical Sciences, Telangana for period of 1 year from August 2019 to July 2020. 100 infertile women with infertility of the age group 20 - 40 years with normal hormone profile and without male factor infertility were included in this study.

\section{Inclusion Criteria}

- Infertile women with primary infertility of the age group 20 - 40 years with normal hormone profile and without male factor infertility.

\section{Exclusion Criteria}

- Infertile women with age less than 18 years or more than 40 years.

- Infertile women with abnormal hormone profile.

- Couples with male infertility.

- Patients with active pelvic infections.
Initially, all women were examined by taking detailed history, physical examination, basic endocrinological investigations, ultrasonography (USG) pelvis. After that general examination, systemic and genital examinations were carried out on patients selected for the study.

Male partner's semen analysis was done and was normal. Each patient was admitted a day prior to the procedure. All the patients were kept nil by mouth (NBM) after $10 \mathrm{pm}$ a day before surgery.

After taking written and informed consent, laparoscopy was performed during the post-menstrual phase on 7th, 8th and 9th day of cycle under general anaesthesia with endotracheal intubation. First, hysteroscopy was performed vagina and cervix were examined for any abnormality (growth, polyp etc.), uterine cavity was examined for the presence of septum, any congenital malformation, fibrotic bands or synechiae, polyps, fibroid, and condition of the endometrium. Both the tubal ostia were visualized and looked for patency.

Pneumoperitoneum was created, and laparoscopy was performed, and the following structures were carefully examined for any abnormality in ovaries, fallopian tubes, pelvic peritoneum, peritoneal cavity, and pouch of Douglas. Uterus was inspected for its shape, size, position, surface, and presence of fibroid. Cul-de-sac was examined for any adhesions, obliteration, endometriotic nodules or fluid. Ovaries were viewed for size, shape, surface, colour, presence of cysts, and relation with tubes. Fallopian tubes were inspected carefully for size, shape, surface, kinking, dilatation, stricture or hydrosalpinx. Any features suggestive of infertility were looked for.

At last, chromopertubation (CPT) was performed to check for tubal patency on both the sides. Methylene blue dye was injected with a $20 \mathrm{ml}$ syringe through Leech Wilkinson cannula. Spillage of the dye from the fimbrial end of tube was visualized. After the procedure, patient was transferred to post-operative ward and was discharged next day.

\section{Statistical Analysis}

The statistical analysis was performed using calculation of percentage by using Microsoft Excel 2010 and Statistical Package for Social Sciences (SPSS) software.

\section{RESULTS}

A total number of 100 patients underwent hysterolaparoscopy out of which $70(70 \%)$ suffered from primary infertility and $30(30 \%)$ suffered from secondary infertility.

\begin{tabular}{|ccc|}
\hline Age in Years & No. of Cases & Percentage (\%) \\
$20-25$ & 18 & $18 \%$ \\
$26-30$ & 47 & $47 \%$ \\
$31-35$ & 23 & $23 \%$ \\
$36-40$ & 12 & $12 \%$ \\
\hline Table 1. Distribution of Infertility Cases & According to Age \\
\hline
\end{tabular}

The present study showed maximum cases of infertility ( $47 \%$ ) in the age group of 26 - 30 years followed by (23\%) cases of infertility in the age group of $31-35$ years. The mean age of patients with infertility was 29.66 years (Table 1 ). 


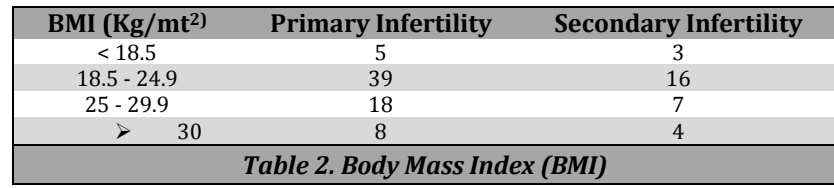

In the primary infertility group, five patients were underweight, eighteen patients were overweight, eight were obese, and the rest had normal body mass index (Table 2). In the secondary infertility group, three patients were underweight, seven patients were overweight, four were obese, and the rest had normal body mass index (Table 2).

\begin{tabular}{|cccc|}
\hline & Primary Infertility & Secondary Infertility & Total \\
\hline Normal & $22(31 \%)$ & $12(40 \%)$ & $\mathbf{3 4}(\mathbf{3 4} \%)$ \\
Endometriosis & $19(27 \%)$ & $4(13 \%)$ & $\mathbf{2 3}(\mathbf{2 3} \%)$ \\
Tubal pathology & $10(14 \%)$ & $4(13 \%)$ & $\mathbf{1 4}(\mathbf{1 4} \%)$ \\
Ovarian pathology & $27(38 \%)$ & $3(10 \%)$ & $\mathbf{3 0}(\mathbf{3 0} \%)$ \\
Adhesions & $10(14 \%)$ & $4(13 \%)$ & $\mathbf{1 4}(\mathbf{1 4} \%)$ \\
Myomas & $7(10 \%)$ & $4(13 \%)$ & $\mathbf{1 1 ( 1 1 \% )}$ \\
Uterine anomalies & $3(4 \%)$ & - & $\mathbf{3 ( 3 \% )}$ \\
Abdominal TB & $1(1 \%)$ & - & $\mathbf{1}(\mathbf{1} \%)$ \\
\hline \multicolumn{2}{|l}{ Table 3. Laparoscopic Findings in Primary and Secondary Infertility } \\
\hline
\end{tabular}

In the primary infertility, ovarian pathology was the most common finding in $38 \%$ of the patients. Ovarian pathology included 15 cases of ovarian cysts (not including endometriotic cysts), 9 cases of poly cystic ovarian syndrome (PCOS) and 3 cases with small ovaries. The second highest abnormality was endometriosis which comprised 19 (27\%) of the patients. Majority 10 (52\%) of the endometriosis was diagnosed to be stage 1 .

Myomas comprised $10 \%$, tubal pathology and pelvic adhesions contributed to about $14 \%$ each. 3 cases of uterine anomalies (two unicornuate uterus with a noncommunicating rudimentary horn and one hypo plastic uterus) were noted and one case of abdominal tuberculosis was diagnosed on laparoscopy.

In both, the group's laparoscopic abnormalities were significant. Twenty-nine patients belonging to primary infertility group and one in secondary infertility had more than one abnormal finding during diagnostic hysterolaparoscopy. One patient in primary infertility group, had findings suggestive of tuberculosis, for example, caseous material in pelvis and visible tubercles on fallopian tubes and pelvic serosa (tuberculosis was confirmed later on by polymerase chain reaction).

In secondary infertility tubal pathology, endometriosis, adhesions and myomas constitute $13 \%$ each.

\begin{tabular}{|cccc|}
\hline Findings & Primary Infertility Secondary Infertility & Total \\
\hline Normal & $37(53 \%)$ & $16(53 \%)$ & $\mathbf{5 3}(\mathbf{5 3} \%)$ \\
Endometrial polyp & $13(18 \%)$ & $4(13 \%)$ & $\mathbf{1 7}(\mathbf{1 7} \%)$ \\
Intrauterine adhesion & $2(3 \%)$ & $3(10 \%)$ & $\mathbf{5 ( 5 \% )}$ \\
Septum / sub septum & $7(10 \%)$ & $2(6 \%)$ & $\mathbf{9 ( 9 \% )}$ \\
Obliterated ostia & $1(1 \%)$ & $1(3 \%)$ & $\mathbf{2}(2 \%)$ \\
Unicornuate uterus & $2(3 \%)$ & 0 & $\mathbf{2}(\mathbf{2} \%)$ \\
Myoma & $7(10 \%)$ & $4(13 \%)$ & $\mathbf{1 1}(\mathbf{1 1} \%)$ \\
Hypoplastic uterus & $1(1 \%)$ & 0 & $\mathbf{1 ( 1 \% )}$ \\
\hline Table 4. Hysteroscopic Findings in Primary and Secondary Infertility \\
\hline
\end{tabular}

On hysteroscopy, 37 of the 70 patients in primary infertility group were found to have normal study. 13 patients (18\%) were diagnosed with endometrial polyp which were the commonest hysteroscopic finding in this group, 7 patients (10\%) were diagnosed to have myomas, uterine septum and sub septum. Intrauterine adhesions were noted in $3 \%$ of the patients while obliterated ostium was noted in 1 patient. 2 patients had unicornuate uterus and 1 patient had a hypo plastic uterus.

$47 \%$ patients with secondary infertility were found to have abnormal hysteroscopic picture. Endometrial polyps and myomas were the leading cause (13 \%) followed by intrauterine synechiae in $(10 \%)$ cases. 2 cases of intrauterine septum were noted and 1 case of obliterated ostium was noted. Intrauterine adhesions were $10 \%$ in the secondary infertility group compared to $3 \%$ in the primary infertility group.

\begin{tabular}{|cccc|}
\hline Findings & Primary infertility & Secondary infertility & Total \\
Unilateral block & $7(10 \%)$ & $5(17 \%)$ & $12(12 \%)$ \\
Bilateral block & $4(6 \%)$ & $4(13 \%)$ & $8(8 \%)$ \\
\hline \multicolumn{4}{|c|}{$\begin{array}{c}\text { Table 5. Chromopertubation Findings } \\
\text { of Primary and Secondary Infertility }\end{array}$} \\
\hline
\end{tabular}

Chromopertubation was done in 99 of the 100 cases $(1$ case of abdominal TB was diagnosed on table and dye test was not performed). $58(84 \%)$ of the 70 primary infertility patients were found to have bilaterally patent tubes. 7 (10\%) of them have unilateral tubal block. 4 (6\%) of them had bilaterally blocked tubes. In the secondary infertility group, 21 (70\%) had patent tubes while 4 (13\%) had blockage on both sides. $5(17 \%)$ of them have unilateral tubal block. There was no significant difference in unilateral or bilateral tubal block between the primary and secondary infertility groups.

Patients did not suffer from any major complication during or after the procedure. Mild abdominal pain in the perioperative site was the only complaint.

\section{DISCUSSION}

Hysterolaparoscopy is minimally invasive techniques reaching new horizons in management of infertile patients. In our study comprising 100 patients, a total of $66 \%$ of patients had abnormal laparoscopic findings and $46 \%$ of patients had abnormal hysteroscopic picture. Hysteroscopy offers a safe diagnostic and therapeutic alternative in the same sitting. Today the complication rate of hysteroscopic procedures has reduced significantly owing to better training skills and anaesthetic techniques. When combined with laparoscopy, hysteroscopic procedures have a complication rate of about $2.35 \% .^{5}$ Apart from minimal bleeding and post procedure discomfort, no other complications were experienced by the patients in this study. The commonest finding was endometrial polyp which was $18 \%$ in primary infertility and $13 \%$ in secondary infertility patients. Other studies have found incidence of endometrial polyps 8 - $18 \%{ }^{6,7,8}$ Though the exact mechanism by which polyps cause sub fertility and pregnancy loss is unclear, proposed mechanisms include mechanical interference with sperm transport, embryo implantation or through intrauterine inflammation or altered production of endometrial receptivity factors. The presence of polyp may hinder implantation and cause infertility. ${ }^{9}$ In a study including 224 female infertile patients, pregnancy rates improved by $50 \%$ after polypectomy. All cases of endometrial polyps found in our study underwent polypectomy. ${ }^{10}$

Apart from polyps, $10 \%$ of women with primary infertility had myomas. The association of infertility and myomas is rather weak when corrected for all other factors. ${ }^{11}$ Correction 
of submucous myomas and other myomas distorting the cavity was undertaken in few selected patients in our study. Septate and sub septate uterus formed the next group of abnormalities noted in our study comprising $10 \%$ and $6 \%$ of primary and secondary infertile patients respectively. Different studies report a range of 5 - $50 \%$ depending on the centre.

Madhuri N et al. reported 7 - $9 \%$ incidence, Nayak PK et al. have reported $10 \%$ incidence, $6 \%$ incidence in Nanaware SS et al. and a higher $50 \%$ incidence in Kabadi YM et al.6,7,8 Practice committee of the American Society for Reproductive Medicine in their 2016 guideline have mentioned that though there is insufficient evidence, hysteroscopic septum incision is associated with improved clinical pregnancy rates in women with infertility. So, in a patient with infertility, prior pregnancy loss, or poor obstetrical outcome, it is reasonable to consider septum incision. ${ }^{12}$ Earlier abdominal procedures were done for septum correction, now advancement in operative hysteroscopy enables us to effectively do a septal resection as a day care procedure with minimal complications. Other hysteroscopic procedures apart from septal resection were polypectomy, submucous myoma resection, adhesiolysis and tubal cannulation. Thus, hysteroscopy provides both diagnostic and therapeutic advantage in the same sitting with minimal complications. ${ }^{5}$

Laparoscopy gives a magnified view of the pelvis, thereby resolving questions about tubal and ovarian morphology, tubal adhesions and also tubal patency. Endometriosis and peritoneal adhesions distort the tubo-ovarian relationship and prevent the ovum pickup even though the tubes appear normal externally. Laparoscopy is the gold standard for diagnosis of these disorders and has the advantage of performing corrective surgery in the same sitting.

The most common finding on laparoscopy was ovarian pathology averaging to $38 \%$ in the primary infertility group and $10 \%$ in the secondary infertility group. Ovarian cysts and PCOS were majority of cases.

Madhuri $\mathrm{N}$ et al. reported $23 \%$ ovarian pathology in primary infertility and $9 \%$ in secondary infertility. Ramesh B et al. reported $18 \%$ ovarian pathology in primary infertility group, Kabadi et al. reported $15 \%$ and Nayak et al. reported 8 $\% .^{13,5,8}$

Endometriosis forms the next largest diagnosis with about $27 \%$ in primary infertility and $13 \%$ in secondary infertility.

In current clinical practice, a surgery, for example, laparoscopy is needed for an authoritative conclusion of endometriosis. Histologic assessment is justified at whatever point the finding isn't evident on visual examination at surgical procedure. ${ }^{14}$ Studies proposed that $25 \%$ to $50 \%$ of women with infertility have endometriosis and that $30 \%$ to $50 \%$ of ladies with endometriosis are infertile. ${ }^{15}$ Female age, span of infertility, pain in pelvic region, and phase of endometriosis ought to be viewed as while forming a treatment plan. The advantage of laparoscopic treatment of negligible or minimal endometriosis is inadequate to prescribe laparoscopy exclusively to improve the probability of pregnancy. At the point when laparoscopy is performed for different signs, the specialist may consider securely removing or extracting obvious lesions of endometriosis.14 Further prospective randomised studies are required to quantify the effect of surgical treatment of endometriosis on pregnancy rates. Tubal disease is an important cause of infertility and needs to be evaluated before starting fertility treatment. ${ }^{16}$ Though hysterosalpingography and saline infusion sonography have been used for diagnosis with varying degrees of accuracy, laparoscopy and chromopertubation is the gold standard. Laparoscopy provides a general view of the pelvic organs and also helps to identify pelvic adhesions. ${ }^{16}$ Laparoscopy is an exceptional test that can determine fimbrial function in addition to the patency of tubes. In our study, tubal pathology was found in $14 \%$ of women with primary infertility and $13 \%$ of women with secondary infertility.

Other studies like Madhuri $\mathrm{N}$ et al. reported tubal pathology of $15 \%$ in primary infertility and $5 \%$ in secondary infertility. Nanaware S et al. reported $43 \%$ tubal pathology whilst Nayak PK et al. reported $8 \%$. $^{13,6}$

Our study reported $6 \% \mathrm{~B} / \mathrm{L}$ block in the primary infertility group and $13 \%$ in secondary group. Madhuri $\mathrm{N}$ et al. reported B/L tubal block of $8 \%$ in primary infertility and $9 \%$ in secondary infertility. Nayak P et al. reporting $12 \%$, Nanaware S et al. who reported $25 \%$ tubal block while Kabadi et al. reported $20 \%{ }^{6,7,8}$ Fallopian tube obstruction is implicated to play a role in $12-33 \%$ of subfertile couples and hence assessment of its patency is crucial in the work up of an infertile couple. ${ }^{17}$

\section{CONCLUSIONS}

Combined hysterolaparoscopy is a safe, effective and reliable method in comprehensive evaluation of infertility. It helps in the diagnosis of pelvic pathology which is missed by routine pelvic examinations and basic investigations done for evaluation of infertility. Hysterolaparoscopy becomes the "Third eye of the gynaecologist" in diagnosing infertility and gives the added advantage of doing a therapeutic procedure in the same sitting. We conclude that combined hysterolaparoscopy is one of the most important procedures in the evaluation of female infertility.

Data sharing statement provided by the authors is available with the full text of this article at jemds.com.

Financial or other competing interests: None.

Disclosure forms provided by the authors are available with the full text of this article at jemds.com.

\section{REFERENCES}

[1] Chanu SM, Pal GSR, Panda S, et al. Diagnostic hysterolaparoscopy for evaluation of infertility: our experience in a tertiary Care Hospital. J Hum Reprod Sci 2018;11(1):19-23.

[2] Ganguly S, Unisa S. Trends of infertility and childlessness in India: findings from NFHS data. Facts Views Vis Obgyn 2010;2(2):131-8.

[3] Mehta AV, Modi AP, Raval RM, et al. Role of diagnostic hysterolaparoscopy in the evaluation of infertility. Int J Reprod Contracept Obstet Gynecol 2016;5(2):437-40.

[4] Madhuri N, Rashmi HS, Sujatha MS, et al. Role of diagnostic hysterolaparoscopy in the evaluation of female infertility. Int J Res Med Sci 2019;7(5):1531-5.

[5] Roupa Z, Polikandrioti M, Sotiropoulou P, et al. Causes of infertility in women at reproductive age. Heal Sci J 2009;3(2):80-7. 
[6] Ramesh B, Kurkuri SN. The role of combined hysterolaparoscopy in the evaluation of female infertility as one step procedure: a retrospective analytical study of 250 patients. Int J Reprod Contracept Obstet Gynecol 2016;5(2):396-401.

[7] Nayak PK, Mahapatra PC, Mallick J, et al. Role of diagnostic hysterolaparoscopy in the evaluation of infertility: a retrospective study of 300 patients. J Hum Reprod Sci 2013;6(1):32-4.

[8] Nanaware SS, Saswade M, Shende PN, et al. Role of hysterolaparoscopy in the evaluation of female infertility in tertiary care centre. International Journal of Contemporary Medical and Research 2016;3(10):3063-5.

[9] Kabadi YM, Harsha B. Hysterolaparoscopy in the evaluation and management of female infertility. J Obstet Gynaecol India 2016;66(Suppl 1):478-81.

[10] Al Chami A, Saridogan E. Endometrial polyps and subfertility. J Obstet Gynaecol India 2016;67(1):9-14.

[11] Shokeir TA, Shalan HM, EI-Shafi MM. Signifinace of endometrial polyps detected hysteroscopically in enumenorrheic infertile women. J Obstet Gynacol Res 2004;30(2):84-9.
[12] Practice Committee of the American Society for Reproductive Medicine in Collaboration with the Society of Reproductive Surgeons. Myomas and reproductive function. Fertil Steril 2008;90(5):S125-30.

[13] Miller JHN, Weinberg RK, Canino NL, et al. The pattern of infertility diagnosis in women of advanced reproductive age. Am J Obstet Gynecol 1999;181(4):952-7.

[14] Practice Committee of the American Society for Reproductive Medicine. Uterine septum: a guideline. Fertil Steril 2016;106(3):530-40.

[15] Practice Committee of the American Society for Reproductive Medicine. Endometriosis and infertility: a committee opinion. Fertil Steril 2012;98(3):591-8.

[16] Missmer SA, Hankinson SE, Spiegelman D, et al. Incidence of laproscopically confirmed endometriosis by demographic, anthropometric and lifestyle factors. American J Epidemiol 2004;160(8):79-96.

[17] Practice Committee of American Society of Reproductive Medicine. Diagnostic evaluation of infertile female: a committee opinion. Fertil Steril 2015;103(6):e44-50. 